\title{
O Welfare State resiste? \\ Desenvolvimentos recentes do estado social nos países da OCDE
}

\author{
Is the Welfare State resisting? \\ Recent developments of the social state in OECD countries
}

Celia Lessa Kerstenetzky ${ }^{1}$

Graciele Pereira Guedes ${ }^{2}$
${ }^{1}$ Instituto de Economia, Universidade Federal do Rio de Janeiro. Av. Pasteur 250, Urca. 22290-902 Rio de Janeiro RJ Brasil. celiakersten@gmail.com ${ }^{2}$ Faculdade de Economia, Centro de Estudos Sociais Aplicados,Universidade Federal Fluminense. Niterói RJ Brasil.

\begin{abstract}
In this paper an attempt was made to analyze some of the main indicators of the evolution of the welfare state in OECD countries between 1980 and 2016. In particular, an assessment was made to evaluate if the so-called Great Recession starting in 2008 led to a contraction of the social state. The analysis focused on three dimensions: social expenditure, funding, and effectiveness. The conclusion drawn was that the twenty-first century has been a period of expansion, both in terms of social expenditure and the catch-up of the latecomers. In particular, all traditional areas of social policy have expanded in tandem with a slight increase in "active" social policies. The rise in social expenditure has been financed by increasing taxation not thoroughly alien to progressivity principles. Overall, it has been translated into an increased effort for redistribution. However, inequality and poverty are advancing at a higher rate.
\end{abstract}

Key words Welfare State, Organisation for Economic Co-Operation and Development, Inequality, Taxation, Poverty
Resumo Neste artigo buscamos analisar alguns dos principais indicadores da evolução do estado de bem-estar social em países da OCDE entre 1980 e 2016. Em particular, buscamos avaliar se a crise iniciada em 2007-2008 teria implicado em contração do estado social. Nossa análise se desdobra no estudo do comportamento de três dimensões: o gasto social, seu financiamento tributário e sua efetividade. Nossa investigação revela que o século XXI tem sido um período de expansão, com gastos crescentes e "catch up" de países retardatários. Em particular, todas as grandes áreas de politica social sofreram aumentos, ao lado de apostas ainda incipientes em politicas sociais "ativas". O gasto social tem sido financiado por um esforço tributário crescente, não de todo indiferente à progressividade, e tem se traduzido em crescente esforço de redistribuição. Contudo, desigualdades e pobreza avançam em ritmo superior.

Palavras-chave Estado do bem-estar social, Organização para a cooperação e desenvolvimento econômico, Desigualdade, Tributação, Pobreza 


\section{Introdução}

Neste artigo nos propusemos a documentar e analisar alguns dos principais indicadores da evolução do estado do bem-estar social no mundo desenvolvido. Embora o arco temporal compreenda, em um extremo, a década de 1980 e, no outro, os anos mais recentes para os quais há dados disponíveis, nosso interesse inicial foi registrar as reações à Grande Recessão, que teve início em 2007-2008 e se materializou em taxas de crescimento nulas ou negativas do PIB no bloco de países que integram a OCDE nos anos de 2008 e 2009. Em poucas palavras, teria a crise implicado em contração do estado social?

Mas, a motivação última de nossa análise foi buscar um quadro de referência o mais amplo e robusto possível para situar a decisão brasileira de engessar o gasto social pelos próximos 20 anos, estabelecendo desse modo limite rígido e incontornável para a expansão da política social bem como dinâmica conflitiva entre seus elementos centrais - opondo expansões eventuais de uma política a contrações necessárias em outras.

Nossa análise se desdobra no estudo do comportamento de três dimensões: o gasto social, seu financiamento tributário e sua efetividade. A escolha dessas dimensões se deve à compreensão do estado de bem-estar como o arranjo que dá corpo ao pacto social cujo intuito é fixar o conjunto de bens primários sociais a ser provido publicamente e garantido por financiamento solidário. Sabemos que esses arranjos institucionais variam e sempre que possível e cabível nossa análise fará referência a diferenciações ou regimes de provisão.

$\mathrm{Na}$ dimensão do gasto social, documentamos a evolução do gasto como percentual do PIB, buscando observar se tal evolução representou variação de recursos reais, se ocorreu em todas as principais rubricas e se há alguma variação significativa em termos de grupos de países. Neste estudo, tentaremos também identificar aspectos qualitativos desse gasto, mudanças ou permanências na concepção de bem-estar social: em particular se há tendência a algum tipo de residualismo, à manutenção da ênfase em proteção social (por exemplo, aposentadorias, pensões, gastos com incapacidades) ou ainda a políticas produtivistas (aquelas voltadas para aumentar a participação econômica dos indivíduos). Para tal propósito, será de grande utilidade a investigação dos diferentes "clusters e regimes" de bem-estar existentes nos países desenvolvidos.

Para isto seguiremos a classificação sugerida por Esping-Andersen ${ }^{1}$, que divide países de- senvolvidos nos seguintes grupos, segundo seus diferentes regimes de provisão: regime liberal (Estados Unidos, Reino Unido, Austrália, Canadá e Nova Zelândia), regime conservador (Áustria, Bélgica, França, Alemanha e Holanda) e regime social democrata (Dinamarca, Suécia, Noruega e Finlândia). Além desses grupos, incluímos dois países asiáticos (o Japão e a Coreia), o grupo dos 10 países menos desenvolvidos da OCDE - aqueles com os menores índices de desenvolvimento humano do bloco (Grécia, Estônia, Polônia, Chile, Eslováquia, Portugal, Hungria, Letônia, Turquia e México) e o grupo dos “demais países". Usamos as expressões grupo ou cluster intercambiavelmente, e "regimes" apenas para os países classificados por Esping-Andersen. Também nos referiremos ao regime social democrata como cluster ou grupo nórdico ou, simplesmente, os nórdicos.

Com relação à tributação, a ideia é observar não apenas a evolução da carga tributária, como também tentar captar alterações significativas na forma como o estado social é financiado. Do mesmo modo que sobre o gasto pesa a profecia de "corrida para o fundo", também o mesmo se passa com a tributação: o mundo globalizado, com liberdade plena de movimentação do capital, pressionaria a capacidade dos governos de cobrar tributos. Contudo, as receitas tributárias, como os gastos, seguem se expandindo. Com a trava representada por um gasto social crescente, a questão crucial passa a ser não tanto "a quanto montam os tributos", mas "quem os paga”. A previsão sombria é que consumidores, indivíduos e trabalhadores carregariam o peso dos tributos, tornando-os menos progressivos. Em nosso estudo dinâmico, buscamos então identificar se teria havido mudança na distribuição de encargos entre: impostos diretos e indiretos; impostos pagos por indivíduos e por corporações; contribuições pagas por trabalhadores e por empregadores. A análise da evolução das alíquotas máximas também ajudará a esclarecer esse ponto.

Finalmente, nossa atenção se voltará a fatos que indiquem resultados palpáveis da provisão pública de bens primários sociais. Destacaremos como indício da efetividade do estado social contemporâneo o que chamamos de "esforço de redistribuição": o tamanho da redução da pobreza e da desigualdade, obtido por meio das transferências e impostos diretos do estado social.

A análise está longe de exaustiva. Aspectos de economia política, da política social e da dinâmica das instituições e das reformas do welfare state, incluindo alterações em regras de elegibilidade, 
tamanho de benefícios, carências, articulação entre financiamento público e provisão, enfim detalhes onde normalmente o diabo habita, não puderam ser considerados neste artigo, não apenas por questões de espaço, mas por adicionar complexidade a temas já de si bastante espinhosos. O objetivo mais modesto foi o de documentar a evolução recente de indicadores como um primeiro passo, não obstante necessário, para o enfrentamento das grandes questões que desde sempre rondam o estado de bem-estar.

\section{A evolução do gasto social}

\section{O gasto total}

Preliminarmente, os dados relativos ao gasto social são apresentados segundo a metodologia adotada pela OCDE, que exclui as despesas com educação primária, secundária e terciária, mas inclui aquelas com educação infantil, estas como integrantes da rubrica "família”. Descrevemos essas rubricas no Quadro 1. Deve-se, contudo, ressaltar que essa exclusão contrasta com a tradição seja dos trabalhos sobre gasto social no Brasil e na América Latina, seja da literatura canônica do welfare state, na qual a educação tem papel de destaque. Para nos mantermos em linha com essas duas tradições, apresentaremos também os dados que incluem os gastos com educação. Enquanto os gastos sociais "OCDE" foram computados a partir da base de dados dessa organização, para as despesas com educação nos baseamos na série construída pelo Banco Mundial, que cobre todo o nosso período de análise. Tal inclusão nos permitirá uma análise qualitativa para além de questões afeitas exclusivamente à proteção social e ao trabalho, valorizadas pela primeira metodologia. Posteriormente, nos voltaremos para a análise por rubricas do gasto, cujo ano mais recente selecionado é 2013, já que para anos posteriores a série é mais esparsa, excluindo vários países.

A observação da evolução do gasto social como \% do PIB revela expansão quase que ininterrupta desde 1980 até o ano 2016 (Gráfico 1). Sabe-se que essa não é a única maneira de medir o gasto, havendo várias medidas possíveis, cada uma assinalando um aspecto dessa dinâmica. Neste artigo, optamos pela métrica mais comum,

Quadro 1. Rubricas do gasto público social + Educação.

\begin{tabular}{|c|c|}
\hline Velhice & $\begin{array}{l}\text { Comporta o gasto com os itens de aposentadorias, aposentadorias precoces, cuidado } \\
\text { residencial/serviços de auxílio domiciliar, outros benefícios monetários, como subsídios, e } \\
\text { outros benefícios in kind (serviços de assistência social para pessoas idosas, por exemplo). }\end{array}$ \\
\hline Pensões & $\begin{array}{l}\text { Engloba o gasto com itens de aposentadorias, despesas funerárias e outros tipos de } \\
\text { benefícios in kind e monetários (compensações para viúvas de artistas, por exemplo). }\end{array}$ \\
\hline Incapacidades & $\begin{array}{l}\text { Abarca o gasto social com os itens de pensões por invalidez, aposentadorias por acidente de } \\
\text { trabalho e licenças remuneradas devido a doenças. }\end{array}$ \\
\hline Saúde & $\begin{array}{l}\text { Refere-se ao gasto social total com benefícios monetários e in kind relacionados a cuidados } \\
\text { com a saúde. }\end{array}$ \\
\hline Família & $\begin{array}{l}\text { O gasto social total com as famílias comporta o gasto com subsídios familiares, licenças } \\
\text { maternidade e parental, outros benefícios monetários, isenções fiscais; e ECEC: comporta } \\
\text { o gasto com itens relacionados ao cuidado infantil, tais quais o cuidado em instituições } \\
\text { (centre-based day-care), cuidado domiciliar (family day care), e programas de pré-escola } \\
\text { (pre-school early education programmes). }\end{array}$ \\
\hline $\begin{array}{l}\text { Políticas ativas } \\
\text { de mercado de } \\
\text { trabalho }\end{array}$ & $\begin{array}{l}\text { O gasto social total com políticas ativas de mercado de trabalho comporta o gasto com } \\
\text { administração e serviços públicos de emprego, treinamento, rotatividade da mão-de-obra e } \\
\text { compartilhamento de trabalho. }\end{array}$ \\
\hline Desemprego & $\begin{array}{l}\text { O gasto social total com o desemprego comporta o gasto com pagamentos compensatórios/ } \\
\text { indenizações e aposentadorias precoces por razões ligadas ao mercado de trabalho. }\end{array}$ \\
\hline Habitação & $\begin{array}{l}\text { O gasto social total com habitação comporta o gasto com assistência à moradia e outros } \\
\text { benefícios in kind, como subsídios de habitação às famílias. }\end{array}$ \\
\hline $\begin{array}{l}\text { Outras áreas da } \\
\text { política social }\end{array}$ & $\begin{array}{l}\text { O gasto social total com outras áreas da política social comporta o gasto com manutenção } \\
\text { de renda, assistência social, outros benefícios monetários (relacionados à requisição de asilo } \\
\text { e a imigrantes, por exemplo), e outros benefícios in kind. }\end{array}$ \\
\hline Educação & $\begin{array}{l}\text { O gasto total com educação se refere aos três níveis (primário; secundário; terciário). O } \\
\text { gasto do governo com educação (corrente, de capital, e proveniente de transferências) inclui } \\
\text { o gasto financiado por transferências de fontes internacionais para o governo nos níveis } \\
\text { local, regional e central. }\end{array}$ \\
\hline
\end{tabular}

Fonte: elaboração própria. 


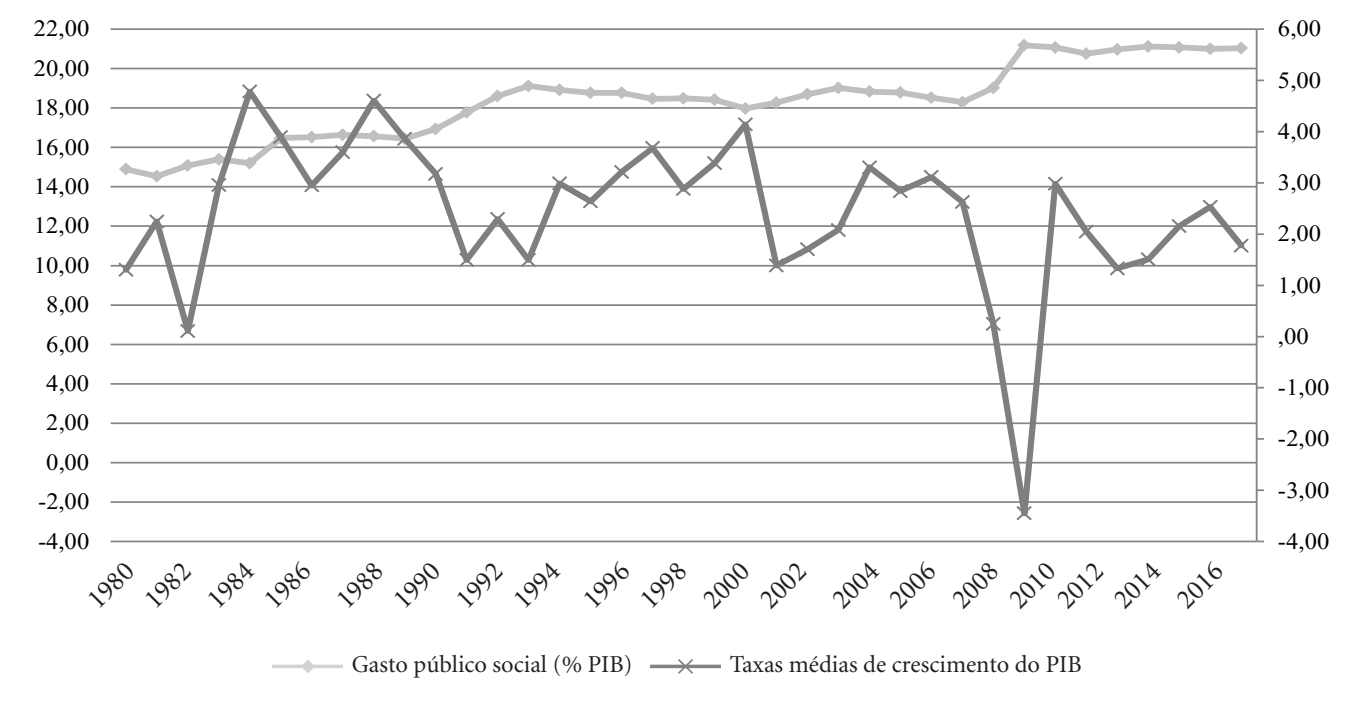

Gráfico 1. Gasto Público Social (\%PIB) e Taxas Médias de Crescimento do PIB dos países da OCDE - 1980-2016.

Fonte: OECD SOCX²/OECD Stats³. Elaboração Própria.

Nota: o gasto público social está plotado no eixo à esquerda e as taxas de crescimento do PIB estão plotadas no eixo à direita.

o gasto como proporção do produto, que sinaliza a prioridade que as sociedades conferem a essa forma de utilização da riqueza gerada a cada ano. Ao compilarmos concomitantemente séries de evolução do produto, pudemos identificar momentos de contração que poderiam representar um comprometimento menor de recursos (apresentamos uma delas no Gráfico 1).

Nossa análise concluiu que a proporção do gasto seguiu crescendo no bloco da OCDE, mesmo quando o produto não crescia ou mesmo se contraía, nos anos de 2008 e 2009, evidenciando, nesse caso, um maior esforço do estado social justamente para compensar a maior demanda e os menores recursos, devidos ambos à recessão. Contudo, nos anos seguintes, com crescimento positivo do PIB, a proporção do gasto não retorna ao nível anterior à recessão, estabelecendo-se em um patamar mais elevado, chegando a atingir em 2016 um valor médio superior a 21\% do PIB. Esse "efeito-catraca" da dinâmica do gasto social acompanha praticamente toda a história do estado de bem-estar.

Destacam-se, em particular, os 10 países menos desenvolvidos, que têm expansões superiores à média do bloco, sobretudo ao longo do presente século, e Japão e Coreia com incrementos igualmente espetaculares.
As fontes de crescimento são várias, nem todas diretamente relacionadas a crises. Por exemplo, mudanças demográficas, como o envelhecimento populacional (expectativas de vida maiores, menores taxas de fecundidade), mudanças nos arranjos familiares, avanço na participação econômica das mulheres, mudanças estruturais na economia e seus múltiplos impactos sobre o mundo do trabalho - todos esses fatores incidem fortemente sobre a demanda de bem-estar, que, ao se ampliar, se vê amparada em titularidades. Em conjuntura de crise, evidentemente, outras carências se acrescentam - de assistência, serviços, seguros -, e se constituem em novas fontes de crescimento.

Outro fator frequentemente mencionado na literatura, e que se coaduna com essa dinâmica liderada pela demanda, é a chamada nova política do welfare state: trata-se da proteção de políticas e programas sociais conferida pelas clientelas que delas se beneficiam e que acabam se constituindo, em contexto democrático, em obstáculo político para reformas de retração paradigmáticas $^{4}$. Contudo, para além dessas fontes inerciais de crescimento ou de trava ao de-crescimento, há que mencionar novas iniciativas de política social relativas ao trabalho e especialmente às famílias (Quadro 1). 
Um segundo ponto é notar que praticamente todas as principais áreas de políticas sociais avançaram à frente do PIB, as exceções notáveis sendo o gasto com incapacidades ("incapacity") e o seguro desemprego, a partir da segunda década do século atual, que, como gastos essencialmente contracíclicos, caíram com a recuperação econômica recente.

As duas políticas mais importantes, as voltadas para a "velhice" (old age), cujo principal item são as aposentadorias, e aquelas dirigidas à saúde apresentaram crescimento ao longo de todo o período, com subida pronunciada, especialmente como reação à crise, a partir do subperíodo 20002008. Ou seja, o aspecto "proteção social" do welfare state tradicional seguiu dominante, acompanhando a dinâmica demográfica. No caso das políticas para a velhice, cabe destacar a centralidade dessa intervenção, não apenas para garantir o bem-estar de idosos, mas também como força auxiliar na redução das desigualdades de renda, cada vez mais necessária em virtude da inversão da pirâmide demográfica.

Não obstante a permanência das intervenções tradicionais, novas políticas ganham força, ao longo do século XXI, com destaque para as políticas voltadas para as famílias e, nelas, as intervenções voltadas para a primeira infância (ECEC, da sigla em inglês Early Childhood Education and Care). Uma narrativa cada vez mais difundida é que intervindo mais cedo na vida dos cidadãos o estado social pode contribuir mais eficazmente para viabilizar a proteção social deles ao longo da vida, mas especialmente quando idosos.

Se adicionarmos a educação ao gasto social OCDE, seguindo a praxe dos estudos lationamericanos e da literatura de welfare state, constataremos que também ela contribuiu para que o gasto avançasse sobre o produto dos países do bloco. A educação passou a consumir 0,5 ponto de PIB a mais entre 1980 e 2010-2013, alcançando a média de $5 \%$ no período final. O gasto social total, incluindo a educação, atinge em 2015 patamar superior a $26 \%$ do PIB.

Em síntese, a partir da análise dos dados, foi possível verificar que: (1) a expansão foi generalizada nos diferentes grupos de países; (2) houve uma "corrida para cima", com os países retardatários diminuindo a distância dos líderes; e (3) a liderança nórdica é inconteste a partir da década de 1990 (Tabela 1).

\section{Mudanças estratégicas?}

Para checarmos a hipótese de ter havido mudanças estratégicas nos estados de bem-estar, analisaremos a evolução da composição do gasto social em termos das diferentes rubricas registradas na base de dados da OCDE.

Ao contrário do que se poderia esperar, "novos tempos, novas políticas", a análise revelou mais continuidade que mudança no estado social contemporâneo: o aumento em importância das rubricas tradicionais de proteção social, como velhice e, principalmente, saúde, e a redução no seguro desemprego e nas políticas ativas de mercado de trabalho (sempre muito incipientes). A novidade, como já mencionado, se fez representar pela expansão das políticas de família, o que foi observado em quase todos os grupos de países, e com força especial no Reino Unido, na Coreia e na Dinamarca, sendo líderes os países escandinavos, com $3,4 \%$ do produto destinados a elas em 2013 (3,7\% na Dinamarca).

A educação, por sua vez, apesar de sofrer pequena elevação como percentual do PIB, perde

Tabela 1. Gasto Público Social + Educação (\%PIB): médias de regimes e grupos de países - 1980-2013.

\begin{tabular}{lcccc}
\hline \multicolumn{1}{c}{ Países/Anos } & Década 1980 & Década 1990 & $\mathbf{2 0 0 0 - 2 0 0 9}$ & $\mathbf{2 0 1 0 - 2 0 1 3}$ \\
\hline Regime Liberal & 19,5 & 22,1 & 22,5 & 24,6 \\
Regime Conservador & 28,2 & 28,9 & 29,9 & 31,9 \\
Regime Social-Democrata & 22,5 & 32,0 & 30,6 & 32,8 \\
10 Países Menos Desenvolvidos OCDE & 11,0 & 16,4 & 19,7 & 22,0 \\
Países Asiáticos & 15,6 & 10,8 & 15,9 & 19,4 \\
Demais Países & 22,3 & 21,8 & 23,8 & 26,3 \\
OCDE & 20,2 & 23,0 & 23,7 & 26,0 \\
\hline
\end{tabular}

Fonte: The World Bank/Unesco ${ }^{5}$ (gasto público com educação)/OECD SOCX ${ }^{6}$ (gasto público social). Elaboração própria. 
posição relativa no gasto total, o que pode ser efeito de mudanças na composição demográfica. De todo modo, também na rubrica educação, os países escandinavos são os líderes em gastos, superando em média 6,5\% do PIB em 2014 e 25\% do gasto social total em 2013 - Nova Zelândia, Austrália e Canadá superam a Dinamarca em termos de proporção do gasto, mas ficam bem atrás quando observamos a proporção do produto destinada à educação.

A fim de discernir os caminhos recentes do estado social, a análise da evolução do gasto pode ser enriquecida pela agregação das políticas sociais em dois conjuntos distintos, as políticas passivas e as políticas ativas. Essa distinção não é arbitrária. Na literatura é comum considerar-se o welfare state que emerge do segundo pós-guerra europeu como um arranjo voltado essencialmente para a proteção contra riscos sociais, envolvendo principalmente, ainda que não exclusivamente, benefícios monetários, ao passo que o estado social contemporâneo teria evoluído na direção de enfatizar políticas de ativação da população, que a dirigissem para a inserção no mercado de trabalho (uma referência seminal é o trabalho de Esping-Andersen et al. ${ }^{6}$ ). Neste último caso, os serviços seriam os ingredientes relevantes para preparar a população para se converter em trabalhadores produtivos e a ênfase em benefícios monetários tenderia a desaparecer.

Essa separação é, não obstante, algo artificial, pois mesmo políticas de proteção social são prenhes de serviços e políticas ativas operam não apenas com serviços, mas fazendo uso de benefícios monetários. Contudo, tem certa utilidade analítica, pois permite-nos observar permanências ou mudanças que, por sua vez, sinalizem combinações ou substituições entre conjuntos de políticas com objetivos distintos.

Tentamos, pois, captar esses movimentos distinguindo como políticas passivas o conjunto que compreende "velhice, incapacidades e pensões" e políticas ativas como aquelas voltadas para a "família e mercado de trabalho". As primeiras se destinam a cobrir riscos relacionados a situações de perda de capacidade de gerar rendimentos e assumem a forma principalmente de benefícios monetários, enquanto as últimas têm foco na participação econômica dos indivíduos e em sua produtividade.

Dentre as políticas de família, a educação e os cuidados infantis se destacam. Vários trabalhos têm documentado a importância de creches e pré -escola para permitir a participação econômica das mulheres, além de promover o desenvolvi- mento infantil e contribuir para mitigar a iniquidade de gênero, seja no mercado de trabalho, seja na divisão do trabalho reprodutivo ${ }^{7,8}$. Essas iniciativas têm sido apontadas também como relevantes para a redução de desigualdades intra- e inter-geracionais, neste último caso contribuindo para amenizar a transmissão das desigualdades por meio das famílias. Contudo, a variedade de arranjos produz efeitos diferenciados nos países do bloco em termos do alcance desses objetivos, variando de programas que permitem a plena desfamiliarização de cuidados e desenvolvimento infantil de qualidade a, no outro extremo, outros que apenas facilitam a atividade econômica das mulheres e reforçam maternalismos ou ainda dualismos nas oportunidades de desenvolvimento infantil ${ }^{9}$.

Já as políticas ativas de mercado de trabalho têm sido consideradas medida eficiente de qualificação e requalificação para o trabalho, com o potencial de promover mobilidade ocupacional e chances de realização por meio do trabalho, com impactos favoráveis sobre a produtividade, a desigualdade salarial e, eventualmente também, sobre o nível de desemprego ${ }^{10}$. Os países nórdicos foram pioneiros nessas políticas. A difusão delas no âmbito da OCDE tem sido matizada pelas características e propósitos dos diferentes regimes de bem-estar: quando adotadas no regime liberal, visam à inserção imediata no mercado de trabalho; no regime conservador, elas têm reforçado dualismos na força de trabalho; entre os países do regime social democrata, elas têm funcionado em combinação com a economia do conhecimento ampliando a mobilidade ocupacional.

Ao analisarmos a distribuição de prioridades com a lente fornecida pela distinção entre políticas passivas e ativas não constatamos alteração significativa ao longo das últimas três décadas. Embora as primeiras tenham perdido posição relativa, continuam vigorosas, respondendo por cerca de 49\% do gasto social em 2013 (eram $52,5 \%$ na década de 1980 ), enquanto as políticas ativas sofreram pequena elevação, para $12,7 \%$ do gasto social (a partir de 12\% na década de 1980). E muito embora as políticas de família tenham adquirido certo destaque, as políticas ativas de mercado de trabalho que já eram incipientes na década de 1980 (0,6\% do PIB) se contraíram ligeiramente (para 0,5\% em 2013), revelando-se uma aposta quase que exclusivamente nórdica. De fato, a Dinamarca, que é líder em 2013, optou por um incremento de 1 ponto percentual de PIB, dedicando quase $2 \%$ do produto a esse conjunto de políticas. Seguindo o exemplo nór- 
dico, a Coreia experimentou expansões bastante significativas.

Com relação à família, como já mencionado, as ECEC são as políticas dominantes. Elas se expandem na OCDE principalmente no século XXI, dobrando como \% do PIB em 30 anos e multiplicando por 2,5 sua participação no gasto social. No período, o líder inquestionável desse gasto, que atinge $1,3 \%$ do PIB e $5 \%$ do gasto social em 2013, são os países nórdicos, que na verdade já o ostentavam desde os anos 1930. A vice-líder, em 2013, é a pioneira Suécia, com 1,6\% do PIB; mas a liderança geral coube à Islândia, com 1,8\%. Vale mencionar que esse gasto se expande em todos os grupos de países aqui considerados, com notáveis desenvolvimentos da Nova Zelândia e do Reino Unido, no regime liberal; da França, que tem gastos nórdicos, no regime conservador; e entre os asiáticos, da Coreia. Os EUA permanecem como retardatários, enquanto Alemanha e Áustria, com gastos ainda baixos, começam a convergir no século XXI. Mas o salto mais impressionante se deu nos 10 países menos desenvolvidos do bloco, que em média multiplicaram por 7 a parcela do PIB dedicada a essas políticas.

Vale observar que os países nórdicos mantêm a combinação políticas passivas-políticas ativas praticamente inalterada. São os países com os maiores percentuais de participação de ambos os conjuntos de políticas no gasto social público considerando os três regimes de bem-estar: $52,3 \%$ e $17,1 \%$, respectivamente. O Reino Unido, que vem investindo em políticas de família, reduziu o ritmo de crescimento das políticas passivas, com ligeiro acréscimo nas ativas, enquanto os EUA reduziram as despesas com políticas ativas, mas realizaram a maior expansão na saúde em pontos percentuais de produto - o que é em boa parte explicado por elevação substancial dos custos ${ }^{11}$. A combinação nórdica é plena de sentido: na disputa pelo significado do estado social como um estado de investimento social, a opção nórdica, ao contrário da inglesa, tem sido combinar (não substituir) a seguridade social com políticas ativas - construir "pontes", não "trampolins".

Uma última observação é que se somarmos os gastos nórdicos com educação e ECEC, o total remonta a $7,8 \%$ do PIB, sempre, de longe, os maiores gastos nessas rubricas do bloco da OCDE, que ainda se elevaram 1,2 ponto de PIB desde a década de 1980. Esse resultado é consistente com a opção do cluster por uma abordagem de "educação ao longo da vida", a qual inclui, ainda, os investimentos da rubrica "políticas ativas de mercado de trabalho" em políticas de qualificação e requalificação de trabalhadores, estejam eles desempregados ou não. De novo, essas intervenções integram a visão do estado de bem-estar como investimento social - sem, contudo, descurar de seus aspectos tradicionais de manutenção de renda e bem-estar ${ }^{8,10,12}$.

\section{E o financiamento, como evoluiu?}

Entre a década de 1980 e o ano de 2016, a carga tributária média da OCDE avançou 10 pontos sobre o produto, alcançando $34,3 \%$ do PIB dos países. O avanço foi substancial em todos os grupos e espetacular nos países menos desenvolvidos (16 pontos) e entre os nórdicos (13 pontos) - este último cluster já detinha no início da série, e continua a ostentar ao final dela, a maior carga do bloco (43\% em 2016, com destaque para a Dinamarca, 45\%) (Tabela 2). É preciso mencionar que no confronto com o gasto social, todos os clusters e grupos de países já destinavam no início deste século mais da metade da receita tributária às despesas do estado de bem-estar: 56,6\% na média do bloco, variando de 50,3\%, no grupo asiático, a $63,2 \%$, no cluster nórdico. Isso assinala não

Tabela 2. Carga Tributária média (\% PIB) por regimes e grupos de países - Década 1980 a 2015.

\begin{tabular}{lcccc}
\hline \multicolumn{1}{c}{ Países/Anos } & Década 1980 & Década 1990 & $\mathbf{2 0 0 0 - 2 0 0 9}$ & $\mathbf{2 0 1 0 - 2 0 1 5}$ \\
\hline Regime Liberal & 30,3 & 31,0 & 30,7 & 29,4 \\
Regime Conservador & 39,9 & 40,3 & 39,6 & 40,7 \\
Regime Social-Democrata & 42,4 & 44,4 & 44,1 & 43,0 \\
10 Países Menos Desenvolvidos OCDE & 18,9 & 26,7 & 28,0 & 28,8 \\
Países Asiáticos & 21,5 & 22,7 & 24,5 & 26,5 \\
Demais Países & 30,3 & 32,9 & 34,1 & 33,7 \\
OCDE & 31,6 & 33,1 & 33,3 & 33,3 \\
\hline
\end{tabular}

Fonte: OECD Stats ${ }^{3}$. Elaboração Própria. 
apenas a importância crescente da função redistributiva do gasto público, como a natureza mesma do Estado contemporâneo: um Estado social.

Cabe, contudo, qualificar essa arrecadação não apenas em termos do quanto dela se destina ao financiamento do estado social como quão bem ela se afina com o princípio redistributivo da capacidade de pagar, segundo o qual devem ser mais tributados, absoluta e relativamente, aqueles com maior capacidade econômica.

Para uma primeira abordagem dessa questão, compilamos dados sobre a evolução da composição da carga tributária em termos das oposições tributos diretos e indiretos, impostos diretos corporativos e impostos diretos pessoais, contribuições à seguridade pagas por empregadores ou por empregados, lembrando que, prima facie, os primeiros tendem a ser mais progressivos.

Os impostos diretos sobre a renda, os lucros e os ganhos de capital foram e continuam sendo mais importantes do que os impostos indiretos no bloco como um todo - de fato, mais importantes do que todas as categorias de tributos $(33,7 \%$ da receita tributária no período recente). Contudo, há dois desenvolvimentos dignos de nota: em primeiro lugar, os impostos diretos vêm perdendo importância relativa, diminuindo a distância entre sua participação e a dos impostos indiretos na tributação (cuja participação praticamente não se altera). O segundo movimento é que caiu a participação dos impostos sobre as pessoas em relação aos impostos pagos pelas corporações. $\mathrm{O}$ primeiro desenvolvimento em princípio piora a progressividade, o segundo, é possível que a restaure. Apenas uma análise mais precisa de incidência fiscal poderá dirimir esse ponto.
A dinâmica das contribuiçõoes à seguridade social mostra um aumento substancial de sua participação na carga total na média do bloco, contrabalançando a perda de posição dos impostos diretos, sendo esta (as contribuições) a terceira categoria de tributos mais importante (depois dos impostos diretos e dos indiretos). Essas contribuições, evidentemente, continuam mais a cargo de empregadores do que de empregados. Contudo, a variação não foi simetricamente dividida entre eles, incidindo mais pesadamente sobre os empregados. Isso é verdadeiro para todos os grupos de países, incluindo os nórdicos, que seguem tendo a maior participação de empregadores no financiamento da seguridade social, mas esta se retraiu mais substancialmente nesse grupo, de $82 \%$ em 1980 para $68 \%$ no período recente (a média na OCDE é 57\%) (Tabela 3).

Vale mencionar ainda o ligeiro aumento da participação das contribuições à seguridade social por parte de autônomos e não empregados, sinalizando a crescente heterogeneidade do mundo do trabalho.

Não se identifica, com exceção dos asiáticos, mudança significativa no padrão de financiamento do gasto público tradicional dos clusters liberal, conservador e social democrata. No primeiro, os impostos diretos mantém a liderança (mas a carga tributária é também a mais baixa); no conservador, as contribuições sociais continuam liderando; no social democrata, apesar de serem os impostos diretos os de maior peso, é também nesse regime que os impostos indiretos têm a maior participação. Este é um fato curioso, em se tratando do regime mais igualitário, mas é preciso considerar que nele o consumo público

Tabela 3. Carga tributária - Impostos diretos, indiretos e contribuições à Seguridade Social - OCDE (\% da Receita Tributária).

\begin{tabular}{lcrrr}
\hline \multicolumn{1}{c}{ Impostos e Contribuições/Anos } & Década 1980 & Década 1990 & $\mathbf{2 0 0 0 - 2 0 0 9}$ & 2010-2015 \\
\hline Impostos diretos (Total) & 37,2 & 35 & 34,6 & 33,7 \\
Impostos diretos (Pessoais) & 30,2 & 26,1 & 23,9 & 23,8 \\
Impostos diretos (Corporativos) & 7,8 & 8,1 & 9,7 & 8,9 \\
Impostos Indiretos (Total) & 33,3 & 33 & 32,7 & 32,7 \\
Contribuições à Seguridade Social (Total) & 22,1 & 24,3 & 25,4 & 26,1 \\
Contribuições à Seguridade Social (Empregados) & 7,3 & 8,3 & 8,9 & 9,6 \\
Contribuições à Seguridade Social (Empregadores) & 13,5 & 14,2 & 14,8 & 14,9 \\
Contribuições à Seguridade Social (Autônomos e & 1,6 & 2 & 2,5 & 2,4 \\
não empregados) & & & & \\
\hline
\end{tabular}

Fonte: OECD Stats³. Elaboração Própria.

Nota: os demais impostos que compõem a carga tributária total são 'impostos incidentes sobre a folha de pagamentos e a força de trabalho' e 'impostos sobre a propriedade'. 
tem maior peso do que nos demais e as menores desigualdades econômicas amenizam efeitos eventualmente regressivos de impostos sobre o consumo privado.

Destoando dos demais clusters, o grupo de asiáticos apresenta mudança de padrão de financiamento, o maior componente da tributação se tornando as contribuições sociais - o que não chega a surpreender, visto o maior esforço do estado social, principalmente a partir dos anos 2000, para cobrir áreas com baixo investimento e financiamento tipicamente contributivo, como a velhice (incluindo, notavelmente, os cuidados na velhice).

Finalmente, o comportamento recente das alíquotas fornece algumas pistas quanto às tendências atuais. Ao longo do presente século, o fenômeno que mais chama a atenção é a redução das alíquotas dos impostos corporativos, de cerca de $30 \%$ para $24 \%$ em média ${ }^{30}$, comportamento seguido por todos os grupos e clusters do bloco, o que empresta credibilidade à tese da competição tributária. Por outro lado, uma vez que os impostos corporativos como um todo se expandiram, uma explicação plausível parece ser a expansão da base fiscal, que nesse caso acompanha justamente o aumento da concentração de renda no topo da distribuição ${ }^{14,15}$. O veredito do impacto dessas mudanças sobre a progressividade geral do sistema tributário segue pendente.

\section{Quão efetivo foi o estado social, considerando gasto e tributação?}

O modo usual de verificar a efetividade do estado social e, em particular, como esta evoluiu, é observar o comportamento de indicadores de pobreza e desigualdade após a incidência das transferências governamentais e dos impostos diretos sobre os rendimentos dos indivíduos. Neste trabalho, nosso marcador de pobreza será a pobreza relativa, isto é, a proporção de indivíduos na população que têm rendimentos inferiores à metade da renda mediana - que é a medida tradicional da base de dados da OCDE. Para identificar o comportamento das desigualdades, observaremos a dinâmica do índice de Gini dos rendimentos. Na análise de efetividade, buscaremos verificar (1) se a pobreza e a desigualdade que vigoram "antes do governo", ou pobreza e desigualdade de mercado, se reduziram após a intervenção governamental, (2) o tamanho dessa contração, que denominaremos "esforço de redistribuição", e, finalmente, (3) quão eficaz ela foi para neutralizar as forças de exclusão e divergência.
No âmbito da OCDE, a pobreza de mercado vem se ampliando de modo ininterrupto ao longo das últimas três décadas e, apesar de um crescente esforço de redistribuição (de 13 pp na década de 1980 para 17 pp no período atual, reduzindo a pobreza de $28,5 \%$ para $11,6 \%$ ), a pobreza após o governo vem aumentando também ( $9,1 \%$ na década de 1980 para $11,6 \%$ no período recente). Isto é, o estado social continua bem-sucedido em reduzir a pobreza de mercado, vem fazendo esforços mais profundos para realizar esse propósito, contudo, estes não têm sido suficientes para confrontar as forças de exclusão que operam no âmbito do mercado.

Esta última conclusão é verdadeira para todos os clusters e grupos de países observados. Contudo, notam-se algumas diferenças: o cluster liberal foi o único que reduziu o esforço de redistribuição, o que ocorreu na primeira década do século atual (basicamente, a Austrália no pós-crise); a pobreza após o governo segue sendo mais baixa nos países com o maior gasto social, os pertencentes ao cluster social democrata; os asiáticos tinham níveis de pobreza de mercado relativamente baixos na década de 1980 e redistribuição insignificante, mas veem esses níveis crescer nos anos 1990 e 2000 e respondem com um salto no esforço de redistribuição (Tabela 4).

Situação semelhante acontece com as desigualdades de mercado e as desigualdades após o governo. As primeiras vêm aumentando e apesar de o estado social seguir em seu encalço, com esforços de redistribuição crescentes, não tem sido capaz de compensar essa dinâmica. Em outros termos, as desigualdades de mercado aumentaram 6 pontos de Gini entre a década de 1980 e os anos 2010-2014 (de 41 para 47), mas, enquanto as desigualdades após o governo se contraíam em resposta às intervenções governamentais a cada período, aumentaram de um extremo ao outro da série (de 29,2 para 31,7). Isso aconteceu a despeito do maior esforço de redistribuição (que variou de 11,7 para 15,6 pontos de Gini).

O mesmo se passou em todos os grupos de países, embora, de novo, algumas diferenças sejam perceptíveis. Em primeiro lugar, apesar de as desigualdades de mercado terem se tornado além de mais altas, mais próximas umas das outras, os nórdicos continuam com os níveis mais baixos, na comparação com os demais regimes de welfare - mas se incluirmos os asiáticos, eles caem para o segundo lugar. Também é o grupo nórdico o que ostenta as menores desigualdades pósgoverno, com elevado esforço de redistribuição, sendo este esforço (mas não o resultado dele) 
superado apenas pelo cluster conservador. Chama a atenção ainda o redobrado ânimo do grupo asiático, a maior variação ocorrida no esforço de redistribuição, algo característico do catch up do estado social desses países. Neste último quesito, o grupo dos 10 menos desenvolvidos também se destacou (Tabela 5).

Em síntese, observamos que apesar do maior vigor do estado social, as forças propulsoras das desigualdades e pobreza de mercado continu-

Tabela 4. Pobreza pós-governo (\% da população) e esforço de redistribuição (\%) - médias de regimes e grupos de países (Década de 1980 a 2010-2014).

\begin{tabular}{|c|c|c|c|c|}
\hline \multicolumn{5}{|c|}{ POBREZA PÓS-GOVERNO } \\
\hline Países/Anos & Década 1980 & Década 1990 & 2000-2009 & 2010-2014 \\
\hline Regime Liberal & 8,2 & 12,1 & 12,7 & 12,6 \\
\hline Regime Conservador & 4,5 & 6,8 & 7,9 & 8,4 \\
\hline Regime Social-Democrata & 5,4 & 5,2 & 6,6 & 7,5 \\
\hline 10 Países Menos Desenvolvidos OCDE & 16,9 & 14,5 & 13,9 & 14,2 \\
\hline Países Asiáticos & 12,0 & 13,7 & 15,2 & 15,5 \\
\hline Demais Países & 9,3 & 9,1 & 9,8 & 10,3 \\
\hline OCDE & 9,1 & 10,0 & 11,2 & 11,6 \\
\hline \multicolumn{5}{|c|}{ ESFORÇO DE REDISTRIBUIÇÃO } \\
\hline Países/Anos & Década 1980 & Década 1990 & 2000-2009 & 2010-2014 \\
\hline Regime Liberal & 15,4 & 15,7 & 14,5 & 14,8 \\
\hline Regime Conservador & 21,3 & 22,2 & 22,2 & 23,0 \\
\hline Regime Social-Democrata & 16,8 & 21,9 & 19,7 & 19,4 \\
\hline 10 Países Menos Desenvolvidos OCDE & .. & .. & 15,3 & 15,1 \\
\hline Países Asiáticos & 0,5 & 5,3 & 7,0 & 9,4 \\
\hline Demais Países & 11,8 & 15,7 & 16,1 & 18,3 \\
\hline OCDE & 13,1 & 16,8 & 16,1 & 16,9 \\
\hline
\end{tabular}

Fonte: OECD Stats³. Elaboração própria.

Tabela 5. Desigualdade pós-governo (coeficiente de Gini) e esforço de redistribuição - Por regimes e grupos de países (Década 1980 a 2010-2014).

\begin{tabular}{|c|c|c|c|c|}
\hline \multicolumn{5}{|c|}{ DESIGUALDADE PÓS-GOVERNO } \\
\hline Países/Anos & Década 1980 & Década 1990 & 2000-2009 & 2010-2014 \\
\hline Regime Liberal & 29,0 & 32,7 & 33,7 & 33,9 \\
\hline Regime Conservador & 26,2 & 27,8 & 28,3 & 28,5 \\
\hline Regime Social-Democrata & 21,4 & 22,5 & 25,3 & 25,9 \\
\hline 10 Países Menos Desenvolvidos OCDE & 42,0 & 41,2 & 36,8 & 36,1 \\
\hline Países Asiáticos & 30,4 & 32,3 & 32,1 & 32,0 \\
\hline Demais Países & 28,8 & 28,5 & 29,5 & 29,1 \\
\hline OCDE & 29,2 & 30,9 & 31,8 & 31,7 \\
\hline \multicolumn{5}{|c|}{ ESFORÇO DE REDISTRIBUIÇÃO } \\
\hline Países/Anos & Década 1980 & Década 1990 & 2000-2009 & 2010-2014 \\
\hline Regime Liberal & 13,2 & 14,4 & 13,7 & 13,8 \\
\hline Regime Conservador & 19,5 & 18,7 & 18,8 & 19,5 \\
\hline Regime Social-Democrata & 16,7 & 19,9 & 18,6 & 18,1 \\
\hline 10 Países Menos Desenvolvidos OCDE & .. & .. & 12,7 & 14,1 \\
\hline Países Asiáticos & 4,1 & 8,0 & 7,7 & 9,5 \\
\hline Demais Países & 14,2 & 16,9 & 16,2 & 17,8 \\
\hline OCDE & 11,7 & 14,2 & 14,6 & 15,6 \\
\hline
\end{tabular}

Fonte: OECD Stats ${ }^{3}$. Elaboração própria. 
aram operando com firmeza. Certamente, um conjunto de fatores de natureza estrutural está por trás dessas dinâmicas, mas nossa atenção aqui se volta para a esfera possível de atuação do estado social. Não podemos, pois, deixar de mencionar a incidência de fatores como a desregulamentação dos mercados de trabalho, que tem exercido efeitos substanciais sobre o incremento da pobreza no trabalho e dos diferenciais salariais.

Apenas como advertência, a análise de efetividade aqui empreendida incide apenas sobre as transferências monetárias do estado de bem-estar e os impostos diretos arrecadados pelo governo e que em parte irão financiar essas despesas. O impacto da arrecadação de outros tipos de impostos, em particular os indiretos e as contribuições, bem como o das despesas com serviços de variada natureza providos pelo estado social, estão excluídos dessa avaliação. Certamente, muitas intervenções do estado social podem estar influenciando a renda de mercado dos indivíduos, por exemplo, os gastos com educação, ou ainda as próprias transferências de renda, que podem afetar decisões quanto à oferta de trabalho. Mesmo assim, parte considerável da diferença de 4 pontos de Gini da desigualdade de mercado entre os nórdicos e os liberais encontra explicação nos baixos prêmios à educação dos primeiros e os altos prêmios concedidos pelos últimos.

\section{Comentários Finais}

Sim, o welfare state resiste, mas precisa de reforços se o objetivo for colocar desigualdade e pobreza sob controle. De fato, as piores profecias podem ser afastadas: o estado social não encolheu, ao contrário dilatou-se; a tributação acompanhou essa expansão e não se traduziu necessariamente em redução de progressividade (para uma afirmação peremptória seria necessária uma análise de incidência fiscal, mas os indícios preliminares vão na direção mencionada); o estado social aumentou o esforço de redistribuição, revelando-se ainda vigoroso. Não fora ele o mundo desenvolvido estaria próximo do nível das desigualdades fratricidas que acometem partes substanciais do mundo subdesenvolvido. Contudo, se com a análise dos indicadores aqui documentados não pudemos detectar sintomas claros de decadência interna do estado social, não deixamos de observar que as forças da mercantilização seguem no seu encalço, redobrando riscos, vulnerabilidades, privações, pobreza e desigualdades.
Em realidade, estamos diante de um duplo desafio. Por um lado, seguir buscando identificar as intervenções mais efetivas, que deverão por esse motivo orientar esforços de catch up social - nesse quesito, nosso estudo revela que o regime social-democrata, tipicamente universalista, continua sendo esse horizonte. É significativo que, em que pesem forças de mercado a impor certa homogeneização dos indicadores de pobreza e desigualdade de mercado no interior do bloco da OCDE, as intervenções do estado social obtenham resultados diferenciados, reforçando a percepção da presença de distintos regimes de bem-estar social nos países desenvolvidos. A anatomia dessas intervenções e o estudo de sua evolução são essenciais para a apreensão dos efeitos benignos, algo que requer análise minuciosa dos traços institucionais dos diferentes regimes de bem-estar, o que não pudemos fazer aqui. Uma análise dessa variedade encontra-se em Kerstenetzky ${ }^{16}$.

Por outro lado, há o desafio de conceber novas áreas e métodos de intervenção para de fato submeter desigualdades e pobreza ao controle das escolhas sociais. E aqui, as esferas regulatória e tributária são as candidatas mais fortes a reformas contundentes. Temos em mente a re-regulamentação dos mercados de trabalho e reformas tributárias que restaurem a progressividade dos tributos (sim, os sistemas tributários dos países desenvolvidos já foram bem mais progressivos!) - em particular, a questão da progressividade emerge como a grande lacuna dos desenvolvimentos contemporâneos do welfare state. Melhorar o equilíbrio entre capital e trabalho, orientação genérica do welfare state universal em sua origem no pós-guerra, parece seguir sendo a melhor prescrição para um estado social efetivo.

Retornando à motivação para a investigação que deu origem a este artigo, preocupam sobremaneira as decisões recentes do governo e do Congresso brasileiros de barrar a expansão do gasto social, o que na prática representará sua contração em termos de proporção da riqueza anual, expansão que, como vimos, tem sido o principal dique a conter desigualdades e pobreza desabridas no mundo contemporâneo. Soma-se a essa iniciativa a reforma da legislação trabalhista aprovada em 2017, que institucionaliza condições precárias de informalidade no emprego. Deve-se ainda acrescentar a ausência na agenda governamental de qualquer preocupação em tornar progressivo um sistema tributário altamente regressivo, baseado em impostos indiretos, com poucos tributos progressivos - o principal deles, 
o imposto de renda, regressivo nas altas rendas ${ }^{17}$. Quando observamos o esforço de convergência que vem sendo levado a cabo pela maioria dos países menos desenvolvidos da OCDE podemos rapidamente compreender porque o Brasil não figurará sequer na última posição do clube dos desenvolvidos.

\section{Referências}

1. Esping-Andersen G. The Three Worlds of Welfare Capitalism. Cambridge: Polity Press; 1990.

2. The OECD Social Expenditure Database (OECD SOCX). [acessado 2017 Set 28]. Disponível em: http:// www.oecd.org/social/expenditure.htm

3. The OECD Statistics (OECD Stats). [acessado 2017 Set 28]. Disponível em: http://stats.oecd.org/

4. Pierson P. The New Politics of the Welfare State. World Polit 1996; 48(2):143-179.

5. The World Bank. [acessado 2017 Out 09]. Disponível em: http://databank.worldbank.org/data/reports.aspx? source $=$ Education-Statistics- $\sim$-All-Indicators

6. Esping-Andersen G, Duncan G, Hemerijck A, Myles J. Why we need a new welfare state. Oxford: Oxford University Press; 2002.

7. Esping-Andersen G. The Incomplete Revolution: Adapting to Women's New Roles. Cambridge, Malden: Polity Press; 2009.

8. Morel N, Palier B, Palme J, organizadores. Towards a Social Investment Welfare State?: Ideas, policies and challenges. Chicago: Bristol, Policy Press; 2012.

9. Kerstenetzky CL. Is the future of social democracy in women's hands? In: Santos IS, Rodrigues PHA, editores. Social risks and policies in Brazil and Europe: convergences and divergences. São Paulo: Hucitec; 2018. p. 217-236.

10. Kerstenetzky CL. Del estado del bienestar keynesiano al estado de bienestar schumpeteriano?: Una agenda socialdemocrata para el siglo XXI. In: Cordera R, Flores M, Fuentes ML, organizadores. Mexico Social: Regresar a lo Fundamental. Ciudad de Mexico: Universidad Nacional Autonoma de Mexico; 2015. p. 289-315.

11. Baumol W. The Cost Disease: Why Computers Get Cheaper and Health Care Doesn't. New Haven/London: Yale University Press; 2012.

12. Hemerijck A, organizador. The Uses of Social Investment. Oxford: Oxford University Press; 2017.

\section{Colaboradores}

CL Kerstenetzky participou na análise, interpretação dos dados e redação do artigo. GP Guedes participou na compilação dos dados.
13. Klynveld Peat Marwick Goerdeler (KPMG). [acessado 2018 Jan 19]. Disponível em: https://home.kpmg.com/ $\mathrm{xx} /$ en/home/services/tax/tax-tools-and-resources/tax -rates-online.html.

14. Wulfgramm M, Bieber T, Leibfried S. Introduction: Welfare State Transformation and Inequality in OECD Countries. In: Wulfgramm M, Bieber T, Leibfried S, organizadores. Welfare State Transformations and Inequality in OECD Countries. London: Palgrave Macmillan; 2016. p. 1-16.

15. Seelkopf L, Lierse H. Taxation and Inequality: How Tax Competition Has Changed the Redistributive Capacity of Nation-States in the OECD. In: Wulfgramm M, Bieber T, Leibfried S, organizadores. Welfare State Transformations and Inequality in OECD Countries. London: Palgrave Macmillan; 2016. p. 89-110.

16. Kerstenetzky CL. O Estado do Bem-Estar Social na idade da razão. Rio de Janeiro: Elsevier; 2012.

17. Pinheiro HH, Waltenberg F, Kerstenetzky CL. Imposto sobre a renda das pessoas físicas: oportunidades para tributar os rendimentos mais altos no Brasil. In: Afonso JR, Lukic MR, Orair RO, Silveira FG, organizadores. Tributação e Desigualdade. Belo Horizonte: Letramento; 2017. p. 261-292.

Artigo apresentado em 01/02/2018

Aprovado em 12/03/2018

Versão final apresentada em 02/04/2018 